\title{
Applying the theory of planned behavior to determine factors associated with physical activity by women with hypertension in rural areas of Iran
}

\author{
Effat Hatefnia ${ }^{1, *}$, Kobra Alizadeh², Mostafa Ghorbani ${ }^{3,4}$
}

\begin{abstract}
Background: Hypertension is the leading preventable cause of premature deaths worldwide. Physical activity reduces the levels of blood lipids and blood pressure in people suffering from hypertension.

Objectives: To apply the theory of planned behavior (TPB) to determine factors associated with physical activity by women with hypertension who were referred to health care centers in Kiashahr in 2016.

Methods: The present observational study was conducted in a cross-section of 215 women diagnosed with hypertension who had records in health care centers in Kiashahr and who were recruited through census from August to September 2016. The data collection tool was a custom-designed questionnaire based on the TPB, and the collected data were analyzed using descriptive and analytical statistical methods.

Results: The mean scores of knowledge, attitudes, subjective norms, perceived behavioral control, and intention to undertake physical activity were significantly $(P<0.01)$ higher among women who performed regular physical activity than in those without regular physical activity. Constructs including behavioral intention $(P<0.001$, odds ratio (OR) $1.36,95 \%$ confidence interval $(\mathrm{CI}) 1.15,1.61)$ and attitude $(P=0.004$, OR $1.27,95 \%$ CI $1.08,1.50)$ were significant predictors for undertaking physical activities.

Conclusions: Attitude and behavioral intention were predictors for undertaking physical activities. We recommended the design of interventional programs based on these 2 factors for women with hypertension living in rural areas of Iran.
\end{abstract}

Keywords: exercise, hypertension, Iran, rural population, women

Hypertension is one of the most important risk factors for atherosclerosis, cerebrovascular accident, and heart and renal failure in many countries, and the leading cause of preventable premature deaths worldwide $[1,2]$. Hypertension refers to intermittent and continuous increase of blood pressure in an individual through which his or her systolic blood pressure

*Correspondence to: Effat Hatefnia, School of Public Health, Alborz University of Medical Sciences, Karaj 3146883811, Iran, e-mail: e.hatefnia@ abzums.ac.ir

'Social Determinants of Health Research Center, Alborz University of Medical Sciences, Karaj 3146883811, Iran

${ }^{2}$ Department of Health Education and Promotion, School of Public Health, Alborz University of Medical Sciences, Karaj 3146883811, Iran

${ }^{3}$ Non-communicable Disease Research Center, Alborz University of Medical Sciences, Karaj 3146883811, Iran

${ }^{4}$ Chronic Diseases Research Center, Endocrinology and Metabolism Population Sciences Institute, Tehran University of Medical Sciences,

Tehran 1417614418, Iran

O Open Access. (c) 2018 Effat Hatefnia et al., published by Sciendo. (c) BY-NC-ND This work is licensed under the Creative

Commons Attribution NonCommercial-NoDerivatives 4.0 License. 
might continuously be $\geq 140 \mathrm{~mm} \mathrm{Hg}$ and diastolic blood pressure might be $\geq 90 \mathrm{~mm} \mathrm{Hg}$ [3]. Hypertension itself accounts for 7 million premature deaths worldwide [4]. The number of people suffering from hypertension worldwide is estimated at 1 billion, of whom $37.6 \%$ are men and $40.1 \%$ are women. Women are more prone to hypertension in old age and during menopause [5, 6]. Various studies show that lack of knowledge about blood pressure is a problem for those attending primary care services [6]. According to the reports issued by the World Health Organization (WHO), the prevalence of hypertension has increased in Asia and Oceania in recent decades [7]. In Iran, various studies show a high prevalence of hypertension; the results of a study by the Endocrinology and Metabolism Center in Tehran showed that the prevalence of hypertension among the age group of 20-69 years was $22 \%$ [4]. It is now widely accepted that hypertension can be prevented and controlled through lifestyle changes [1]. Clinical trials have reported several lifestyle modifications that can reduce hypertension [1]. The corrective measures include weight loss, physical activity, not smoking, eating a healthy diet rich in fruits and vegetables, and reducing sodium intake $[1,7]$. Promoting a less sedentary lifestyle to increase physical activity and thus reduce noncommunicable diseases such as cardiovascular diseases and hypertension is warranted [7].

Physical activity reduces the levels of blood lipids and blood pressure in people with hypertension [8]. Rahmani Ghobadi and Hoseini reported that regular participation in sports and appropriate physical activity might prevent the development of risk factors for cardiovascular diseases such as hypertension, being overweight, and obesity [9]. Despite the benefits of exercise, 1 of every 4 adults in the world does not do sufficient physical activity [10] and this inactivity is observed more among women than men [11]; $79.2 \%$ of women in the age group of 25-34 years in Iran do not do sufficient physical activity [12]. Because rural women, particularly in Asian countries, which for the most part have a similar culture, are less concerned about their own health and care more about the health of their family, they are less likely to do physical activity [13-16]. Hence, the risk of hypertension among rural women in Asia is higher than that in others elsewhere.

Considering the importance of the effect of physical activity on blood pressure control and the lack of a desirable level of physical activity, especially in rural women in Asia, and also considering the vulnerability of these women because of low literacy or illiteracy, lack of assertion of their rights, and that these women consider their health as a second priority to the health of their family, ultimately, due to limited access to the health systems in rural areas, these women may not pay sufficient attention to physical activity to control their blood pressure. With the aim of changing the level of their physical activity, the use of behavioral change theories may help to identify the important and influencing factors for behavior related to physical activity, the relationships between these factors, and the key elements for interventions in this regard $[15,17]$. Several studies have shown that the theory of planned behavior (TPB), a psychological-social theory, is a successful perceptual framework for the physical activity of women [18-22] because this theory includes perceptual beliefs to control the factors that inhibit or facilitate physical activity [23]. TPB has been found typically to explain $41 \%-46 \%$ of the variance in physical activity intentions and $24 \%-36 \%$ of behavioral variance [18]. Identifying behavioral predictors of physical activity would assist TPB-based research for promoting and maintaining physical activity in women in Asia [23].

Few studies of the physical activity by women living in rural areas of Iran have been conducted thus far, and so there are scant data. The available data indicate a general insufficiency of physical activity by women in urban Iran [12], and this likely extends to women in rural areas of Iran. Therefore, in present study, we applied the TPB to understand factors associated with physical activity in women with hypertension in rural areas of Iran. This theory includes study of the attitudes that constitute the base of psychology and the investigation of the groups influencing behavior related to physical activity that constitute the base of sociology [24]. This theory is based on the principle that individuals in a society make reasonable and rational decisions on the basis of available information [24]. TPB represents $77 \%$ of the intention and $17 \%$ of the actual behavior related to physical activity [18]. Various predictions of intention and behavior by the TPB may result from various surveys of behavior and target groups. The TPB consists of 4 constructs: attitudes, subjective norms, perceived behavioral control, and behavioral intention [24]. This theory postulates 3 conceptually independent determinants of intention. By contrast, attitudes, subjective norms, and perceived behavioral control are all potential predictive factors of intention to engage in a particular behavior. According to the TPB, the single best predictor of a person's behavior is the intention to perform that behavior $[24,25]$. Attitude results from an individual's opinions about an issue and evaluation of the responses associated with those opinions. Attitude refers to the individual's positive and negative evaluations of performing some behavior, and different people have different attitudes toward an issue (e.g., with regular physical activity, my blood pressure is controlled; a high-fat diet is harmful to my health) [24]. Subjective norms address evaluating the effect of the ideas of others on performing some behavior and provide some standards for accepting or rejecting a behavior (e.g., my friends do not eat high-fat foods) [24, 26]. Gholamnia et al. showed that subjective norms are the most important predictors of physical 
activity behavior [18]. Perceived behavioral control indicates the perception of whether or not a behavior is under the intentional control of an individual. Perceived behavioral control refers to an individual's perception of the ease or difficulty of performing the behavior of interest (e.g., despite the high interest in a high-fat diet, I can continue avoiding this diet).

An important factor in the TPB is that an individual's intention to perform a particular behavior can change over time (e.g., I want to stop eating a high-fat diet over the next month) [24]. In general, the more favorable the attitude and subjective norms in relation to the behavior and the greater perceived behavioral control, the stronger the individual's intention to perform the behavior will be. It is expected that the relative importance of attitude, subjective norm, and perceived behavioral control to predict intention is different for various behaviors and situations. Therefore, in some applications, we may find that only attitude has a significant effect on intention; in others, attitude and perceived behavioral control are sufficient to create intention, and in other applications, all 3 predictors are effective.

Other studies have examined the prevalence of hypertension and factors affecting the blood pressure of women who live in rural regions, applying the TPB in the present study sought to determine effective factors associated with regular physical activity. Preventing behaviors associated with the incidence of hypertension based on the TPB has been examined in several studies, including those conducted by Pooreh and Hosseini Nodeh [26], who suggested the use of the TPB as an important tool to predict and control the factors associated with the incidence of hypertension and its complications [18, 24]. Therefore, given the importance of controlling hypertension in women, we studied the role of physical activity in controlling the disease. Because few studies in this field have been conducted in rural areas of Iran [18], the aim of the present study was to examine the factors influencing physical activity in women with hypertension living there.

\section{Materials and methods}

\section{Participants}

The present observational study was conducted in a cross-section of 215 women with hypertension. Sampling was achieved through census from August to September 2016, and the subjects were all women diagnosed with hypertension who had health records in health care centers in Kiashahr. The study protocols were approved by the ethics committee of the Alborz University of Medical Sciences on June 6, 2016 (approval No.
Abzums. Rec. 1395.23). All women participating in the study were assured of the confidentiality of their personal data, and they all provided their informed consent that was documented on a specific form. Their blood pressure was measured by primary care providers once a month and by physicians every 6 months. The medical team assisting these women comprised a cardiologist, internist, nutritionist, and neurologist. The inclusion criteria for the study were high blood pressure in women aged $>30$ years who had health records in the health care centers in Kiashahr, and the exclusion criteria were conditions and diseases that limited their physical activity, including pregnancy, cardiovascular problems, arthritis, breathing problems, mental illness, disabilities, and debilitating disease.

\section{Data acquisition tools}

The steps to develop the questionnaire based on the TPB were as follows: first, the researcher designed a questionnaire according to the literature [18] and then assessed its validity and reliability. To assess the content validity qualitatively, the questionnaire was provided to 10 experts in the field of health education who checked it for compliance with correct grammatical rules and use of words and applied required changes. To assess content validity quantitatively, a content validity rating (CVR) was used. To apply the rating, the questionnaire was provided to a panel of experts in the fields of health education, psychology, sociology, sports, and internal medicine. Their opinions regarding necessary or unnecessary questions in the questionnaire were provided. Subsequently, the opinions were compared to a Lawshe table and unnecessary questions were omitted. A content validity index (CVI) was also used to determine content validity by collecting the opinions of the abovementioned panel on relevance, simplicity, and clarity of questions. If the CVI was higher than 0.79 , the assessed question was considered valid, questions with values $0.7-0.79$ were revised, and those with values $<0.7$ were omitted. Cronbach's $\alpha$ was used to confirm the reliability of the questionnaire and was obtained using a pilot population that was approximately $10 \%$ of the sample size. Cronbach's $\alpha$ for the questions was calculated as $80 \%-85 \%$. Construct validity is the result of translation validity and criterion-related validity. Translation validity is processed by face and content validity, which was measured, while criterion-related validity comprises 4 dimensions: concurrent validity, convergent validity, discriminant validity, and predictive validity; none of which have been measured in this study.

The data collection tool in this study comprised 3 parts. The first comprised 9 questions to gather demographic 
information (marital status, age, education, family history of hypertension, childbirth experience, number of children, menopause, and engaging in regular physical activity). The second part comprised 10 questions to assess participants' knowledge (e.g., "whether hypertension is preventable") providing a score ranging from 0 to 10 . Scoring questions related to knowledge assessment was achieved through a binary scale (a score of 0 being for "I do not know" and wrong answers, and a score 1 for correct answers). Knowledge was assessed in a regression model using a $t$ test. The third part comprised questions on constructs of the TPB, including attitude, with a score ranging from 5 to 25 (5 questions, e.g. "I believe that doing physical activity is essential to control my blood pressure"); subjective norms, with a score range of 5-25 (5 questions, e.g., "following recommendations of my physician, I will do regular physical activity"), perceived behavioral control with a score range of 4-20 (4 questions, e.g., "I can schedule my time to do physical activities to control my blood pressure), and behavioral intention with a score range of 3-15 (3 questions, e.g., "I am going to do regular physical activity from next week to control my blood pressure"). Regular physical activity was the dependent variable measured on a binary scale of yes or no. The participants were asked if they engage in regular physical activity. If their reply was positive, they were asked about the type, duration, and interval of their physical activity. The behavior of participants was assessed using WHO guidelines in which adults aged 18-64 years should have moderate activities for at least $150 \mathrm{~min}$ per week ( $30 \mathrm{~min}$ a day for 5 days) or heavy and intense activities for at least $70 \mathrm{~min}$ (20 min per day for 3 days or more) [11]. By showing 3 types of activities, they were asked to determine the type and amount of their activities during the past 7 days (including how many minutes per day and how many days per week). The questions related to the constructs of the TPB, including attitudes, subjective norms, perceived behavioral control, and behavioral intention, were scored on a 5-point Likert-like scale from strongly agree (1) to strongly disagree (5).

Due to regular follow-up programs and provision of health care services for patients with hypertension in health care centers covered by the Health Medical Center of Kiashahr and by considering the medical records of women with hypertension and their self-care behaviors of timely measurement of their blood pressure, they were invited to participate in the study. In the event that they met inclusion criteria for the study, the research objectives and how to complete the questionnaire were explained. Educated patients completed the questionnaire themselves, but those who were not sufficiently educated to complete the questionnaire alone received help from their relatives or other individuals trained in the research objectives.

\section{Statistical analyses}

The data are presented using descriptive statistics (frequency and percentage) and as results of analytical tests. The tests were conducted using PASW Statistics for Windows (version 18; SPSS Inc.) and included an independent $t$ test to compare the mean score of the TPB constructs in hypertensive women with and without qualifying physical activity and logistic regression to determine factors associated with engaging in regular physical activity.

\section{Results}

Most of the participants (86.5\%) were married, and a substantial proportion (39.5\%) was in the age group of 50-59 years. Many participants were illiterate (48.4\%) and $79.5 \%$ identified as housewives; the most frequent (45.1\%) monthly income range was equivalent to USD 125-250 (1 USD equivalent to 31,000 IRR average rate 2016 using https://www.xe.com). About $94.4 \%$ of the women had experienced gestational parity (childbirth) and $96.7 \%$ had insurance. Most had a history of high blood pressure among their relatives (73\%), 74\% were postmenopausal, $34 \%$ had a history of high blood pressure for $<3$ years, and the majority (52.6\%) did not undertake physical activity regularly (Table $\mathbf{1}$ ).

The independent $t$ test results showed that there was a significant difference between the mean scores of knowledge, attitudes, subjective norms, perceived behavioral control, and intention to do physical activity in both groups of women with and without regular physical activities, and those who engaged in regular physical activity had higher scores than the group without regular physical activity for all study variables (Table 2).

Logistic regression was used to assess the impact of the model constructs on engaging in physical activity. The logistic regression included 5 variables: knowledge, attitude, subjective norms, perceived behavioral control, and intention to do physical activities. The general model including all predicting variables was statistically significant $\left(P<0.01, \chi^{2}\right.$ ( $\mathrm{df}=5$, $\mathrm{N}=215)=134.01)$. This shows that the model was capable of differentiating between the participants who reported regular physical activity and those who reported a lack of regular physical activity.

Three variables were associated with the criterion variable of regular physical activity (Table 3). The strongest predictor of the likelihood of doing physical activity was the intention to do physical activity at an odds ratio of 1.36 , suggesting that by controlling all factors in the model, participants who intended to do regular physical activity were 1.36 times more likely to 
Table 1. Demographic characteristics of the participants

\begin{tabular}{|c|c|c|}
\hline & Frequency & Percentage \\
\hline \multicolumn{3}{|c|}{ Marital status } \\
\hline Single & 2 & 0.9 \\
\hline Married & 186 & 86.5 \\
\hline Divorced & 1 & 0.5 \\
\hline Widow & 26 & 12.1 \\
\hline \multicolumn{3}{|l|}{ Education } \\
\hline Illiterate & 104 & 48.4 \\
\hline Primary & 53 & 24.7 \\
\hline Junior & 37 & 17.2 \\
\hline Senior & 13 & 6.0 \\
\hline Academic & 8 & 3.7 \\
\hline \multicolumn{3}{|l|}{ Age (y) } \\
\hline$<40$ & 16 & 7.4 \\
\hline $40-49$ & 43 & 20.0 \\
\hline $50-59$ & 85 & 39.6 \\
\hline$\geq 60$ & 71 & 33.0 \\
\hline \multicolumn{3}{|l|}{ Occupation } \\
\hline Housewife & 171 & 79.5 \\
\hline Farmer & 30 & 14.0 \\
\hline Employee & 8 & 3.7 \\
\hline Retired & 3 & 1.4 \\
\hline Others & 3 & 1.4 \\
\hline \multicolumn{3}{|c|}{ Number of children } \\
\hline $1-3$ & 100 & 49.3 \\
\hline $4-6$ & 73 & 36.0 \\
\hline $7-10$ & 26 & 12.8 \\
\hline$>10$ & 4 & 2.0 \\
\hline \multicolumn{3}{|c|}{ History of hypertension among relatives } \\
\hline Yes & 157 & 73.0 \\
\hline No & 58 & 27.0 \\
\hline \multicolumn{3}{|c|}{ Regular physical activity } \\
\hline Yes & 102 & 47.4 \\
\hline No & 113 & 52.6 \\
\hline
\end{tabular}

Table 2. Independent $t$ test to compare the mean score of the TPB constructs in hypertensive women with and without physical activity

\begin{tabular}{lrrr}
\hline & $\begin{array}{r}\text { Having regular } \\
\text { physical activity } \\
\text { (n= 102); mean } \pm \text { SD }\end{array}$ & $\begin{array}{r}\text { Lack of regular } \\
\text { physical activity }\end{array}$ & $\boldsymbol{P}$ \\
$\mathbf{( n = 1 1 3 )}$; mean \pm SD & \\
\hline $\begin{array}{l}\text { Knowledge } \\
\text { Attitude }\end{array}$ & $20.13 \pm 2.29$ & $8.07 \pm 1.55$ & 0.001 \\
$\begin{array}{l}\text { Subjective } \\
\text { norm }\end{array}$ & $20.93 \pm 2.35$ & $17.35 \pm 3.56$ & 0.001 \\
$\begin{array}{l}\text { Perceived } \\
\text { behavioral }\end{array}$ & $16.64 \pm 2.20$ & $19.85 \pm 2.84$ & 0.003 \\
$\begin{array}{l}\text { control } \\
\text { Intention to }\end{array}$ & $12.46 \pm 2.35$ & $14.05 \pm 2.86$ & 0.001 \\
do activity & & & \\
\hline
\end{tabular}

TPB, theory of planned behavior.
Table 3. Logistic regression to determine factors associated with regular physical activity

\begin{tabular}{lrrrr}
\hline Variable & P & OR & \multicolumn{2}{c}{ 95\% confidence interval } \\
\cline { 5 - 6 } & & & Lower & Higher \\
\hline Knowledge & $<0.001$ & 1.31 & 1.17 & 1.47 \\
Attitude & 0.004 & 1.27 & 1.08 & 1.50 \\
Subjective norms & 0.621 & 0.96 & 0.82 & 1.13 \\
$\begin{array}{l}\text { Perceived behavioral } \\
\text { control }\end{array}$ & 0.623 & 1.05 & 0.87 & 1.25 \\
Intention to do & & & & 1.15 \\
physical activities & $<0.001$ & 1.36 & & 1.61 \\
\hline
\end{tabular}

OR, odds ratio.

engage in regular physical activity compared with those who did not intend to do so. The odds ratio for subjective norms was $<1(0.96)$, suggesting that with an increase in any subjective norm, participants would be less likely to engage in regular physical activity.

\section{Discussion}

Based on the TPB, the aim of the present study was to determine factors associated with regular physical activity by women with hypertension in rural areas of Iran.

We found that the majority of participants $(52.6 \%)$ did not engage in regular physical activity. This finding was consistent with those of Cho et al. who had reported that the majority of their study participants $(62.6 \%)$ from urban regions of Korea did not engage in regular physical activity [27], but not consistent with those of Seyed Emami et al. who found that most volunteers $(63.7 \%)$ in urban Iran engaged in moderate or good levels of physical activity [28]. This difference is probably the result of differences in the participants. In particular, participants in the study by Seyed Emami et al. had higher education, younger age, and were engaged in volunteering jobs, such as being health volunteers, compared with those in the present study.

The independent $t$ test showed that the hypertensive women who engaged in regular physical activity had better knowledge of its beneficial effects than those who did not. This difference can be explained by the education about hypertension from nurses and primary health care providers during the periodic referral of women to the health care centers to receive primary care service. This finding is consistent with those of Zeydi et al. [29] and Sargazi et al. [30], who used the TPB to suggest appropriate interventions to improve the knowledge of women, which might lead to an increased engagement in regular physical activity. 
The hypertensive women who engaged in regular physical activity had a higher positive attitude mean score than those who did not. This difference was consistent with the findings by Pooreh and Hosseini Nodeh who determined that mean scores for attitude in adolescent girls in Iran who engaged in regular physical activity $(41.7 \%)$ were higher than those who did not (34.6\%) [26]. However, it was not consistent with the findings of Seyed Emami et al. and this inconsistency might be due to the differences in education levels of participants in their study in which almost half of volunteers $(48.8 \%)$ had a high school diploma or the difference in the social role of their target group [28].

The hypertensive women who engaged in regular physical activity had higher scores for subjective norms than those who did not. This finding is consistent with those of Jemmott et al. who found higher scores for subjective norms and recommendations from key persons associated with participants who engaged in regular physical activity than for those who did not [31], while Shafieinia et al. found that physical training based on the TPB did not significantly change with mean scores for subjective norms before and after intervention [32]. The reason for this might be the differences between sociocultural features of his participants (female office workers of the Tehran University with better education and employment) and those of women in rural areas of Iran.

The hypertensive women in our present study who engaged in regular physical activity had higher mean scores for perceived behavioral control than those who did not. This finding is consistent with those of the study by Godin et al. [33] and Peddle-McIntyre et al. [34] who found that perceived behavioral control among those who did not engage in regular physical activity could be increased through appropriate health interventions based on the TPB [33, 34]. These findings indicate the importance of perceived behavioral control in modifying health-related behaviors, including regular physical activity, which should be addressed by health educators. If people find physical activity difficult and out of their control, they will not likely to intend to engage in it.

The mean intention score for hypertensive women who engaged in regular physical activity was significantly higher than that for those who did not. This finding was consistent with those of Jalilian et al. [35] and Marsh et al. [36], who found that the mean scores for intention in people who engaged in healthy behavior (physical activity and safe behaviors when crossing a street) were higher than those who did not $[35,36]$.

Attitude had a strong association with regular physical activity by women with hypertension in rural areas of Iran. This finding is consistent with those of Wang and Wang who reported that attitude was a good predictor of engagement in regular physical activity by children [37]. Therefore, educational interventions might focus on a positive attitude. The more a person has a positive attitude toward a behavior, the more desirable, pleasant, useful, and enjoyable the behavior will be. However, this finding was inconsistent with those of Poulter et al. [38] who applied the TPB to truck driving and compliance with regulations. They reported that for compliance with UK truck regulations, perceived behavioral control had the largest direct effect. The incompatibility between the results of this study and the study by Poulter et al. may be explained by behavioral differences in that driving is more difficult than engaging in physical activity.

In the present study, intention had the strongest association with regular physical activity by hypertensive women. Consistent with this, intention was one of the strongest predictors of engaging in regular physical activity by university students [39], patients with type 2 diabetes [40], and university staff [41]. Ajzen and Fishbein also stated that intention predicts actual behavior [42]. Therefore, intention plays an important role in determining physical activity, and this construct should be included in educational interventions [17]. Generally, attitudes, subjective norms, and perceived behavioral control are all potential predictive factors of intention to engage in a particular behavior. According to the TPB, the single best predictor of a person's behavior is the intention to perform that behavior.

Limitations of the present study are that the questionnaire was completed by the target group as a self-report, and some of the rural women may not understand completely the meaning of some questions due to the deficiencies in their literacy, another is that the only participants of the study were women with hypertension who were referred to the health care centers in Kiashahr and had medical records possibly limiting its generalizability. Because this was an observational study of a cross-section of participants, the associations found cannot be attributed as causes. We recommend assessment of the associations using other study types including a trial of educational interventions based on the associations found here.

\section{Conclusions}

The TPB is useful to determine behavioral antecedents related to regular physical activity in women with hypertension. Attitude and intention are the most important predictors of regular physical activity in women with hypertension who live in rural areas of Iran. Mean scores for knowledge, attitude, subjective norms, perceived behavioral control, and behavioral intention among the hypertensive women who engaged in regular physical activity were higher than the scores for those who did not engage in regular physical activity. Women with hypertension 
who have a more positive attitude toward and have a higher intention to engage in physical activity are more likely to engage in regular physical activity. We recommend implementing educational interventions using the TPB with emphasis on the constructs including behavioral intention and positive attitude to promote regular physical activity behavior by women in rural areas of Iran.

Author contributions. EH contributed substantially to the conception and design of the study. KA contributed substantially to the acquisition of data, and MG contributed substantially to its analysis and interpretation. EH drafted the manuscript, and all the authors critically revised it, approved the final version submitted for publication, and agree to take responsibility for the statements made in the published article.

Acknowledgments. The authors thank all the health care center personnel who helped to conduct this study. This research project was sponsored by the School of Health, Alborz University of Medical Sciences.

Conflict of interest statement. The authors have each completed and submitted an International Committee of Medical Journal Editors Uniform Form for Disclosure of Potential Conflicts of Interest. None of the authors has anything to disclose.

\section{References}

[1] Ezzati E, Anoosheh M, Mohammadi E. A study of the effects of group discussion with male high school students on their parents' hypertension control. J Res Health. 2011; 1:64-72. [in Persian, English abstract].

[2] Jarari N, Rao N, Peela JR, Ellafi KA, Shakila S, Said AR, et al. A review on prescribing patterns of antihypertensive drugs. Clin Hypertens. 2016; 22:7. doi: 10.1186/s40885-016-0042-0

[3] MazloomyMahmodabad SS, Agh Atabay R, Movahed M, Jadgal KM, Alizadeh S. Predictive control high blood pressure in patients with hypertension based on health belief model in Kerman in 2015 J Toloo-e-behdasht. 2016; 14:98-106. [in Persian, English abstract].

[4] Baroogh N, Teimouri F, Saffari M, Hosseini Sadeh S, Mehran A. Hypertension and lifestyle in 24-65 year old people in Qazvin Kosar region in 2007]. Pejouhandeh. 2010; 15:193-8. [in Persian, English abstract [Internet]. 2016 [cited 2017 Jun 07]. Available from: $h t t p: / /$ pajoohande.sbmu.ac.ir/browse.php?a_code $=A-10-1-649 \mho s i d=1 \mho s l c_{-}$ lang=en].

[5] August P. Hypertension in women. Adv Chronic Kidney Dis. 2013; 20:396-401.

[6] Katende G, Groves S, Becker K. Hypertension education intervention with Ugandan nurses working in hospital outpatient clinic: a pilot study. Nurs Res Pract. 2014; 2014:710702. doi: $10.1155 / 2014 / 710702$
[7] Skar P, Young L, Gordon C. Changes in blood pressure among users of lay health worker or volunteer operated community-based blood pressure programs over time: a systematic review protocol. JBI Database Syst Rev Implement Rep. 2015; 13:30-40.

[8] McEachan RRC, Lawton RJ, Jackson C, Conner M, Meads DM, West RM. Testing a workplace physical activity intervention: a cluster randomized controlled trial. Int J Behav Nutr Phys Act. 2011; 8:29. doi: 10.1186/1479-5868-8-29

[9] Rahmani Ghobadi M, Hoseini R. The relationship of physical activity and risk factors of coronary heart disease in older men. Iran J Ageing. 2015; 9:316-23. [in Persian, English abstract].

[10] Calogiuri G, Chroni S. The impact of the natural environment on the promotion of active living: an integrative systematic review. BMC Pub Health. 2014; 14:873. doi: 10.1186/1471-2458-14-873

[11] Hallal PC, Andersen LB, Bull FC, Guthold R, Haskell W, Ekelund U, et al. Global physical activity levels: surveillance progress, pitfalls, and prospects. Lancet. 2012; 380:247-57.

[12] Shirvani ZG, Ghofranipour F, Gharakhanlou R, Kazemnejad A. The effectiveness of theory-based multimedia software on exercise behavior and physical activity among women: the Women and Active Life Study. Payesh. 2016; 15:533-47. [in Persian, English abstract].

[13] United Nations. The world's women 1970-1990: trends and statistics. Social statistics and indicators series K, No. 8. New York: United Nations Publication; 1991.

[14] Dutta A, Ray MR. Prevalence of hypertension and pre-hypertension in rural women: a report from the villages of West Bengal, a state in the eastern part of India. Aust J Rural Health. 2012; 20:219-25.

[15] Sun Z, Zheng L, Detrano R, Zhang X, Xu C, Li J, et al. Risk of progression to hypertension in a rural Chinese women population with prehypertension and normal blood pressure. Am J Hypertens. 2010; 23:627-32.

[16] Food and Agricultural Organization. Rural families and farm households in Asia and the Pacific: an overview [online]. 1995 [cited 2017 Mar 30]; United Nations Economic and Social Commission for Asia and the Pacific. Available from: http://www.fao.org/3/ X5211e04.htm

[17] Gholamnia-Shirvani Z, Ghofranipour F, Gharakhanlo R, Kazemnezhad A. Improving and maintaining physical activity and anthropometric indices in females from Tehran: application of the theory of planned behavior. J Educ Community Health. 2016; 2:13-24. [in Persian, English abstract].

[18] Gholamnia Shirvani Z, Ghofranipour F, Gharakhanlou R, Kazemnejad A. Determinants of physical activity based on the theory of planned behavior in Iranian military staff's wives: a path analysis. Global J Health Sci. 2015; 7:230-9.

[19] McEachan RRC, Conner M, Taylor NJ, Lawton RJ. Prospective prediction of health-related behaviours with the Theory of Planned Behaviour: a meta-analysis. Health Psychol Rev. 2011; 5:97-144.

[20] Nunnally J, Bernstein I. Psychometric theory, 3rd ed. New York: McGraw-Hill; 1994.

[21] Francis JJ, Eccles MP, Johnston M, Walker A, Grimshaw JM, Foy R, et al. Constructing questionnaires based on the theory of planned behaviour: a manual for health services researchers. Newcastle upon Tyne: Centre for Health Services Research, University of Newcastle; 2004.

[22] Fishbein M, Ajzen I. Belief, attitude, intention, and behavior: an introduction to theory and research. Reading, MA: AddisonWesley; 1975. 
[23] Baghianimoghadam MH, Gholianavval M, Karimi M, Kamalikhah T, Roohi Moghadam R. Investigating the views of male students on using bicycles based on the theory of planned behavior in Yazd University of Medical Sciences, 2012. Toloo-E-Behdasht. 2014; 13:83-93. [in Persian, English abstract].

[24] Gholami S, Mohammadi E, Pourashraf Y, Sayehmiri K. Evaluating the predictors of fruit and vegetable consumption behavior in Ilam based on constructs of developed planned behavior theory. J Neyshabur Univ Med Sci. 2014; 2:8-18. [in Persian, English abstract].

[25] Ajzen I. The theory of planned behavior. Organ Behav Hum Decis Process. 1991; 50:179-211.

[26] Pooreh S, Hosseini Nodeh Z. Impact of education based on theory of planned behavior: an investigation into hypertension-preventive self-care behaviors in Iranian girl adolescent. Iran J Public Health. 2015; 44:839-47.

[27] Cho S-H, Choi M, Lee J, Cho H. Relationship between expectations regarding aging and physical activity among middle aged adults in urban areas: based on the Pender's Health Promotion Model. J Korean Acad Nurs. 2015; 45:14-24. [in Korean, English abstract].

[28] Seyed Emami R, Ardebili HE, Golestan B. Effect of a health education intervention on physical activity knowledge, attitude and behavior in health volunteers. Hayat. 2011; 16:48-55. [in Persian, English abstract].

[29] Zeidi IM, Hajiagha AP, Zeidi BM. Evaluation of educational programs based on the theory of planned behavior on employees' safety behaviors. J Mazandaran Univ Med Sci. 2013; 22:166-77. [in Persian, English abstract].

[30] Sargazi M, Mohseni M, Safar-Navade M, Iran-Pour A, Mirzaee $M$, Jahani Y. Effect of an educational intervention based on the theory of planned behavior on behaviors leading to early diagnosis of breast cancer among women referred to health care centers in Zahedan in 2013. Iran Q J Breast Dis. 2014; 7:45-55. [in Persian, English abstract].

[31] Jemmott JB 3rd, Stephens-Shields A, O'Leary A, Jemmott LS, Teitelman A, Ngwane Z, et al. Mediation of effects of a theory-based behavioral intervention on self-reported physical activity in South African men. Prev Med. 2015; 72:1-7.
[32] Shafieinia M, Hidarnia A, Kazemnejad A, Rajabi R. Effects of a theory based intervention on physical activity among female employees: a quasi-experimental study. Asian J Sports Med. 2016; 7:e31534. doi: 10.5812/asjsm.31534

[33] Godin G, Bélanger-Gravel A, Amireault S, Vohl M-C, Pérusse L. The effect of mere-measurement of cognitions on physical activity behavior: a randomized controlled trial among overweight and obese individuals. Int J Behav Nutr Phys Act. 2011;8:2. doi: 10.1186/1479-5868-8-2

[34] Peddle-McIntyre CJ, Bell G, Fenton D, McCargar L, Courneya KS. Changes in motivational outcomes after a supervised resistance exercise training intervention in lung cancer survivors. Cancer Nurs. 2013; 36:E27-35.

[35] Jalilian M, Mostafavi F, Mahaki B, Delpisheh A, Rad GS. An application of a theory of planned behaviour to determine the association between behavioural intentions and safe road-crossing in college students: perspective from Isfahan, Iran. J Pak Med Assoc. 2015; 65:742-6.

[36] Marsh HW, Papaioannou A, Theodorakis Y. Causal ordering of physical self-concept and exercise behavior: reciprocal effects model and the influence of physical education teachers. Health Psychol. 2006; 25:316-28.

[37] Wang L, Wang L. Using theory of planned behavior to predict the physical activity of children: probing gender differences. Biomed Res Int. 2015; 2015:536904. doi: 10.1155/2015/536904

[38] Poulter DR, Chapman P, Bibby PA, Clarke DD, Crundall D. An application of the theory of planned behaviour to truck driving behaviour and compliance with regulations. Accid Anal Prev. 2008; 40:2058-64.

[39] Allom V, Mullan B, Cowie E, Hamilton K. Physical activity and transitioning to college: the importance of intentions and habits. Am J Health Behav. 2016; 40:280-90.

[40] Ferreira G, Graça Pereira M. Physical activity: the importance of the extended theory of planned behavior, in type 2 diabetes patients. J Health Psychol. 2017; 22:1312-21.

[41] Jackson C, Andrew Smith R, Conner M. Applying an extended version of the theory of planned behaviour to physical activity. J Sports Sci. 2003; 21:119-33.

[42] Ajzen I, Fishbein M. Understanding attitudes and predicting social behavior. Englewood Cliffs, NJ: Prentice-Hall; 1980. 